\title{
RESULTS OF 102 CASES OF COMPLETE REPAIR OF CONGENITAL HEART DEFECTS IN PATIENTS WEIGHING 700 TO 2500 GRAMS
}

V. Mohan Reddy, MD

Doff B. McElhinney, MD

Theresa Sagrado, BA ${ }^{\mathrm{a}}$

Andrew J. Parry, MD

David F. Teitel, MD

Frank L. Hanley, MD
Background: Published data suggest that low birth weight is a risk factor for poor outcome in corrective surgery for many cardiac defects. Congenital heart defects in low birth weight infants are typically managed with supportive therapy or palliative operations, with definitive repair delayed. The morbidity associated with such approaches is high. Methods: Since 1990 complete repair of congenital heart defects (other than patent ductus arteriosus) has been performed in 102 infants no larger than $2500 \mathrm{~g}$ (median $2100 \mathrm{~g}$, range 700-2500 g), including 16 no larger than $1500 \mathrm{~g}$. Defects included ventricular septal defect $(\mathrm{n}=22)$, tetralogy of Fallot complexes $(n=20)$, transposition complexes $(n=13)$, aortic coarctation $(n=12)$, interrupted $\operatorname{arch}(n=10)$, truncus arteriosus $(n=8)$, atrioventricular septal defect $(n=6)$, total anomalous pulmonary venous return $(n=5)$, and other $(n=6)$. Results: Preoperative morbidity was more common among patients referred late for surgical correction. There were 10 early deaths $(10 \%)$ attributable to cardiac failure $(n=4)$, arrhythmia $(n=1)$, multiorgan failure $(n=1)$, sepsis $(n=$ $1)$, idiopathic coronary artery intimal necrosis $(n=1)$, foot gangrene (n $=1$ ), and pulmonary hemorrhage $(n=1)$. No patient had postbypass intracerebral hemorrhage. At follow-up (median 36 months) there were 8 late deaths, and 8 patients underwent 10 reinterventions. There was no evidence of neurologic sequelae attributable to the operation. Conclusions: In general, delaying repair of congenital heart defects in low birth weight infants does not confer a benefit and is associated with higher preoperative morbidity. Complete repair of both simple and complex lesions can be achieved in such cases with good results. Growth after repair approximates the normal curve for low birth weight infants without heart disease. It is recommended that such infants, especially when they have symptoms, undergo early surgical repair rather than prolonged medical management or other forms of palliation. (J Thorac Cardiovasc Surg 1999;117:324-31) nfants with congenital heart disease are more likely than normal children to have low birth weight $(<2500 \mathrm{~g})$, with estimated rates ranging from $8 \%$ to $18 \% .^{1-3}$ Pre-

From the Divisions of Cardiothoracic Surgery a and Pediatric Cardiology, ${ }^{\text {b }}$ University of California-San Francisco, San Francisco, Calif.

Read at the Seventy-eighth Annual Meeting of The American Association for Thoracic Surgery, Boston, Mass, May 3-6, 1998.

Received for publication May 26, 1998; revisions requested July 6, 1998; revisions received Sept 23, 1998; accepted for publication Oct $15,1998$.

Address for reprints: V. Mohan Reddy, MD, Division of Cardiothoracic Surgery, 505 Parnassus Ave, M593, San Francisco, CA 94143-0118.

Copyright (C) 1999 by Mosby, Inc.

$0022-5223 / 99 \$ 8.00+0 \quad \mathbf{1 2 / 6 / 9 5 3 0 0}$ maturity is often an accompanying condition in these patients; however, many are term infants who are small for gestational age. ${ }^{3}$ Congenital heart disease has been documented to be an important cause of death among premature and low birth weight babies., ${ }^{4,5}$ Previous reports 6,7 have suggested that age and weight are risk factors for poor outcome of corrective operations for many congenital heart defects, supporting the perception among primary caregivers that these small infants are too fragile to withstand cardiopulmonary bypass and surgical correction. In addition there is also a major concern among neonatologists regarding intracranial bleeding after cardiopulmonary bypass, an unproven concern possibly arising from experience with neonatal extracorporeal membrane oxygenation. As a result the 
Table I. Patient demographics

\begin{tabular}{lcc}
\hline & Median & Range \\
\hline Gestational age (wk) & & \\
$\quad$ All patients & 34 & $25-43$ \\
Premature patients $(\mathrm{n}=66)$ & 32 & $25-36$ \\
Age at operation $(\mathrm{d})$ & 16 & $1-137$ \\
Weight at birth $(\mathrm{g})$ & 1970 & $600-2500$ \\
Weight at operation $(\mathrm{g})$ & 2100 & $700-2500$ \\
\hline
\end{tabular}

management course frequently taken when a premature or low birth weight infant is found to have symptomatic congenital heart disease, even if the defect is relatively simple, is delay in definitive surgical intervention, with reliance on supportive therapy or surgical palliation that avoids cardiopulmonary bypass. This course has been justified by the belief that corrective surgery in these tiny infants is technically demanding and that associated issues, such as immature lungs with hyaline membrane disease or an immature central nervous system with the potential for germinal matrix hemorrhage, increase the morbidity associated with cardiopulmonary bypass.

Our approach to infants with symptoms has been to perform total corrective surgical repair whenever biventricular repair is possible. This approach evolved from our experience indicating that these infants often have either associated extracardiac malformations or prematurity-related issues that, when combined with congenital heart disease, lead to severe and often prolonged morbidity when the cardiac defect is not repaired. Because many of these noncardiac problems cannot themselves be corrected immediately, it is intuitively logical that the overall well-being of the infant would be optimized by correcting the cardiac status.

\section{Patients and methods}

Patients. During a period of 7 years from July 1990 to December 1997, 102 low birth weight $(\leq 2500 \mathrm{~g})$ babies with potentially correctable congenital heart defects underwent complete repair. Patients with isolated patent ductus arteriosus were excluded. Weight ranged from 700 to $2500 \mathrm{~g}$ (median $2100 \mathrm{~g}$ ), and 16 patients weighed $1500 \mathrm{~g}$ or less. Median gestational age at birth was 34 weeks, and 66 patients were born prematurely (before 37 weeks' estimated gestational age). Median age at the operation was 16 days (range 1 day to 4.6 months). Demographic data are summarized in Table I.

Techniques. All patients underwent primary complete repair. Median sternotomy was employed in 87 patients and cardiopulmonary bypass was used in 86 . One patient underwent median sternotomy without cardiopulmonary bypass for correction of anomalous right pulmonary artery from the ascending aorta. A lateral thoracotomy approach without car-
Table II. Diagnoses of 102 low birth weight and very low birth weight* infants undergoing complete repair of congenital heart defects

\begin{tabular}{|c|c|c|}
\hline Type & Primary lesion & No. \\
\hline \multirow[t]{8}{*}{ Simple $(n=36)$} & Coarctation of aorta & 12 \\
\hline & With hypoplastic arch $\dagger$ & 8 \\
\hline & Ventricular septal defect & 22 \\
\hline & With subaortic stenosis $\dagger$ & 2 \\
\hline & With atrial septal defect $\dagger$ & 18 \\
\hline & With patent ductus arteriosus $\dagger$ & 17 \\
\hline & $\begin{array}{l}\text { Anomalous right pulmonary } \\
\text { artery from the ascending aorta }\end{array}$ & 1 \\
\hline & Double aortic arch & 1 \\
\hline \multirow[t]{16}{*}{ Complex $(\mathrm{n}=66)$} & Complete atrioventricular septal defect & 6 \\
\hline & With coarctation of the aorta $\dagger$ & 2 \\
\hline & Tetralogy of Fallot & 12 \\
\hline & $\begin{array}{l}\text { Tetralogy of Fallot with pulmonary } \\
\text { atresia }\end{array}$ & 8 \\
\hline & $\begin{array}{l}\text { With major aorta-pulmonary } \\
\text { collaterals } \dagger\end{array}$ & 2 \\
\hline & Truncus arteriosus & 8 \\
\hline & With interrupted aortic $\operatorname{arch} \dagger$ & 1 \\
\hline & Interrupted aortic arch & 10 \\
\hline & $\begin{array}{l}\text { With aorta-pulmonary connection } \\
\text { septal defect } \dagger\end{array}$ & 1 \\
\hline & Transposition of great arteries & 11 \\
\hline & With coarctation of the aorta $\dagger$ & 1 \\
\hline & $\begin{array}{l}\text { Taussig-Bing double-outlet right } \\
\text { ventricle with interrupted arch }\end{array}$ & 2 \\
\hline & $\begin{array}{l}\text { Total anomalous pulmonary venous } \\
\text { return }\end{array}$ & 5 \\
\hline & $\begin{array}{l}\text { Aortic atresia with ventricular } \\
\text { septal defect, absent ascending aorta }\end{array}$ & 1 \\
\hline & $\begin{array}{l}\text { Multiple muscular ventricular septal } \\
\text { defects }\end{array}$ & 2 \\
\hline & $\begin{array}{l}\text { Severe mitral stenosis with } \\
\text { double-orifice mitral valve }\end{array}$ & 1 \\
\hline
\end{tabular}

*Diagnoses of the 16 patients who weighed $1500 \mathrm{~g}$ or less were aortic coarctation $(n=4)$, ventricular septal defect $(n=6)$, tetralogy of Fallot with pulmonary atresia $(n=4)$, total anomalous pulmonary venous return $(n=1)$, and transposition of the great arteries $(n=1)$.

$\dagger$ Associated conditions in patients with the main diagnosis.

diopulmonary bypass was used in the cases of 13 patients (those with coarctation of the aorta and double aortic arch). Two patients with complete atrioventricular septal defect underwent repair of the coarctation (without pulmonary artery banding) through a thoracotomy, followed several days later by repair of the intracardiac defects through a median sternotomy. Standard techniques of neonatal cardiopulmonary bypass were used. ${ }^{8,9}$ Deep hypothermia with circulatory arrest $(\mathrm{n}=23)$ or low-flow cardiopulmonary bypass $(\mathrm{n}=$ 63) was used in all patients who required cardiopulmonary bypass. Since 1993 circulatory arrest has only been used for repair of interrupted aortic arch, in isolation or associated with other anomalies. The mean $( \pm \mathrm{SD})$ duration of cardiopulmonary bypass was $160 \pm 76$ minutes. 


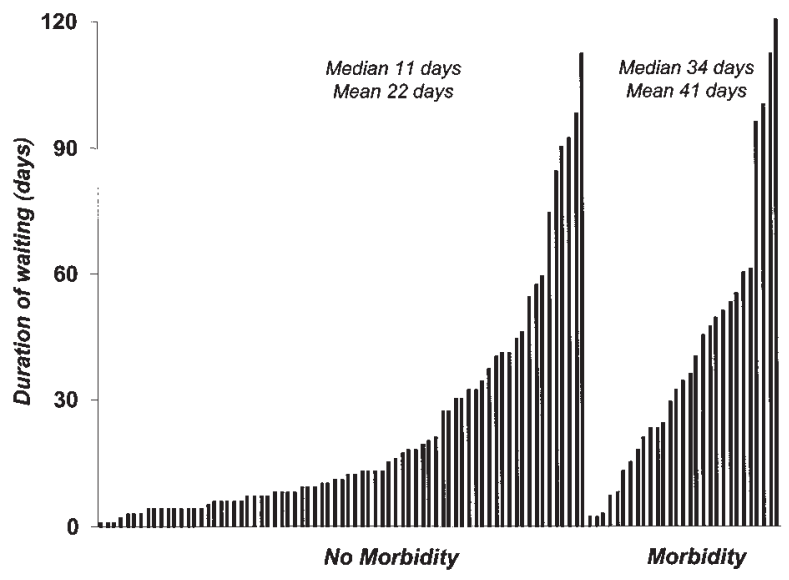

Fig 1. Preoperative morbidity according to the duration of preoperative hospitalization. Specific types of morbidity are listed in Table IV. Each bar represents an individual patient. Bars on the left represent patients who did not have preoperative morbidity, whereas bars on the right indicate patients who did have preoperative morbidity.

Table III. Associated noncardiac malformations or syndromes $(n=30)$

\begin{tabular}{lc}
\hline Malformation or syndrome & No. \\
\hline CATCH-22, DiGeorge syndrome & 7 \\
Trisomy 21 (Down syndrome) & 6 \\
VACTERL association & 2 \\
Gut abnormalities (malrotation, imperforate anus) & 4 \\
Genitourinary anomalies & 3 \\
Turner syndrome & 1 \\
Arnold-Chiari malformation & 1 \\
Holt-Oram syndrome & 1 \\
Familial distichiasis lymphedema syndrome & 1 \\
Diaphragmatic eventration & 1 \\
Other dysmorphism or abnormalities & 7 \\
\hline
\end{tabular}

Because multiple abnormalities were present in some patients, the number of malformations and syndromes listed in this table does not equal 30 , which is the number of patients with associated malformations or syndromes. VACTERL, Vertebral abnormalities, anal atresia, cardiac abnormalities, tracheoesophageal fistula and/or esophageal atresia, renal agenesis and dysplasia, and limb defects.

Data collection and analysis. Perioperative data were obtained through retrospective review of hospital records. Cross-sectional follow-up was performed during the period from September to December 1997 and was complete for all but 2 patients, who were unavailable for follow-up. Followup information, including patient clinical status, weight, medications, and echocardiographic and cardiac catheterization data, was obtained by direct physician or parent contact.

Data are expressed as median and range or mean and SD unless otherwise specified. Comparisons of means between 2 groups were performed with the independent samples $t$ test,
Table IV. Preoperative status and morbidity

\begin{tabular}{lc}
\hline Preoperative status & No. \\
\hline Prolonged failure to thrive* & 13 \\
Prolonged ventilatory support* & 9 \\
${\text { Prolonged prostaglandin } E_{1} \text { infusion* }}^{*}$ & 6 \\
Renal insufficiency & 5 \\
Necrotizing enterocolitis & 4 \\
Prolonged inotropic support* & 5 \\
Multisystem organ failure & 1 \\
Seizures & 3 \\
Stroke & 1 \\
\hline
\end{tabular}

*At least 7 days.

and comparisons of dichotomous variables between 2 groups were performed with $\chi^{2}$ analysis. Actuarial survival analysis and assessment of independent variables correlating with poor survival were performed with the Kaplan-Meier product limit method and Cox proportional hazards regression (univariate and multivariate), respectively. Outcome measures analyzed were perioperative mortality (death during postoperative hospitalization or within 30 days, whichever was longer), late survival, and freedom from reintervention. Preoperative and operative variables analyzed for correlation with outcomes included age, gestational age at birth, birth weight, weight at the operation, time from referral to the operation, diagnosis, complex lesion (defined in Table II), preoperative morbidity, associated syndromes or congenital malformations, cardiopulmonary bypass time, and postoperative open sternotomy. Statistical analysis was performed with SPSS for Windows 6.01 (SPSS Inc, Chicago, Ill).

\section{Results}

Demographic data. Demographic data are summarized in Table I. The distribution of congenital heart lesions is shown in Table II. Lesions were arbitrarily divided into simple $(n=36)$ and complex $(n=66)$. Thirty patients (30\%) had noncardiac malformations or syndromes, as listed in Table III. One patient had congenital complete atrioventricular block in association with interrupted aortic arch.

Preoperative course. Preoperative morbidity was present in 39 patients (Table IV). As shown in Fig 1, preoperative morbidity was more common among patients referred for surgery beyond 2 weeks after the diagnosis. Patients with significant preoperative complications were significantly older at the time of the operation than were patients without such complications $(22 \pm 25$ versus $41 \pm 32$ days, $P=.005)$

\section{Early results}

Early mortality rate. There were 10 early deaths (10\%), only 1 of which was of a patient who weighed less than $1500 \mathrm{~g}$ at the time of the operation. Causes of 

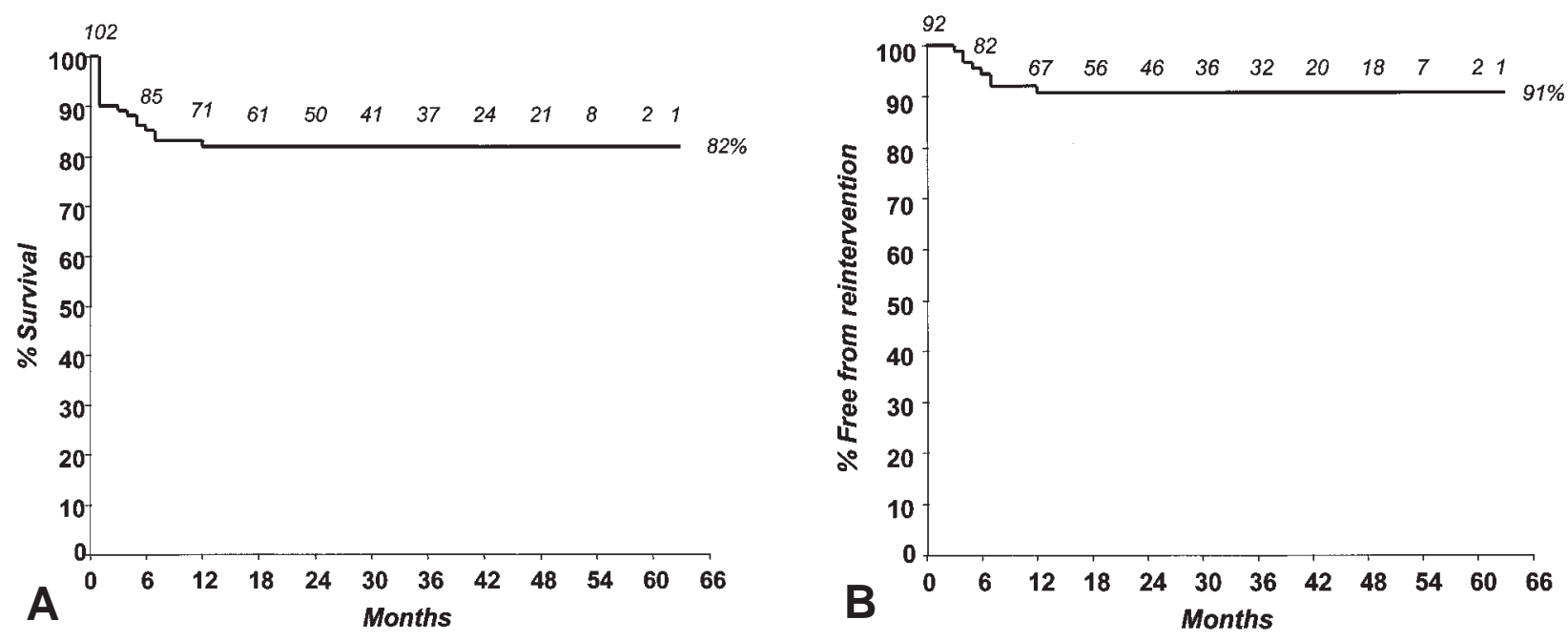

Fig 2. A, Actuarial survival after primary complete repair of congenital heart defects in patients weighing $2500 \mathrm{~g}$ or less. B, Actuarial freedom from reintervention among early survivors of complete primary repair at $2500 \mathrm{~g}$ or less.

death included cardiac failure $(\mathrm{n}=4,2$ with truncus arteriosus, 1 with transposition of the great arteries with coarctation, and 1 with tetralogy of Fallot), arrhythmia ( $\mathrm{n}=1$, tetralogy of Fallot with pulmonary atresia and major aorta-pulmonary collaterals), multiorgan failure $(\mathrm{n}=1$, truncus arteriosus with interrupted arch), sepsis ( $\mathrm{n}=1$, totally anomalous pulmonary venous return), idiopathic coronary artery intimal necrosis ( $\mathrm{n}=1$, transposition of the great arteries), gangrene of the lower extremities ( $n=1$, ventricular septal defect in an 800-g neonate), and pulmonary hemorrhage $(\mathrm{n}=1$, tetralogy of Fallot with pulmonary atresia). Of the preoperative and operative variables analyzed, the only factors found to correlate significantly with early death were longer cardiopulmonary bypass time $(251 \pm 157$ versus $147 \pm 49$ minutes, $P<.001)$ and longer aortic crossclamp time (102 \pm 52 versus $78 \pm 29$ minutes, $P=.01$ ).

Early reinterventions. Five early interventions were performed in 3 patients. One patient (after repair of Taussig-Bing double-outlet right ventricle and interrupted aortic arch) had a right atrial thrombus develop in association with a central venous catheter and required reoperation to evacuate the clot. Later this patient required closure of an atrial septal defect, which had intentionally been left open during the operation to serve as a pop-off right-to-left atrial communication. One patient, in whom a Damus-Kaye-Stansel type of repair was performed for Taussig-Bing anomaly with coarctation of the aorta, acquired native aortic regurgitation and underwent subaortic patch closure of the left ventricular outflow tract. In this same patient a residual left-to-right shunt through the right ventricular trabeculae was closed with coils. One patient underwent reexploration and débridement for mediastinitis.

Other perioperative morbidity. Significant perioperative complications included cardiac arrest in the operating room before the operation $(\mathrm{n}=1$; the patient required extracorporeal membrane oxygenation after repair), complete atrioventricular block $(\mathrm{n}=1)$, temporary phrenic nerve palsy $(n=3)$, central venous thrombus formation $(n=2)$, colonic perforation $(n=1)$, mediastinitis $(n=1)$, and transient seizures $(n=3)$. All 3 patients with transient seizures had a seizure disorder diagnosed before the operation. Four patients acquired sepsis with positive blood culture results and were treated successfully with antibiotics. No patient showed signs of new neurologic abnormalities.

Resource use. Postoperative mechanical ventilation was required for 1 to 75 days (median 5 days). Duration of stay in the intensive care unit ranged from 1 to 85 days (median 9 days). The duration of hospitalization ranged from 5 to 105 days (median 19 days).

\section{Late results}

Follow-up and growth. Follow-up was complete for 88 of 90 early survivors; the other 2 patients were unavailable for follow-up. Follow-up duration ranged from 9 to 54 months (median 30 months). In the cases of 54 survivors for whom copies of the primary pediatrician's growth charts were available, median weight was at the 10th percentile for age-matched healthy children (range <2nd-55th percentile). None of the surviving patients has clinical evidence of postoperative neurologic abnormalities. 
Late mortality rate. There were 8 late deaths (9\% of early survivors). Of these, 4 were of cardiac causes and 4 were of noncardiac causes. One patient died 3 months after the operation of progressive pulmonary venous obstruction of individual pulmonary veins, which had not been present at the time of the original repair. Serial echocardiograms documented the onset and progression of this problem after the initial operation. One patient died 5 months after the operation of right ventricular failure that developed as the patient outgrew the small right ventricular outflow tract conduit that was placed at the initial operation. This patient did not undergo timely reintervention to replace the conduit. In 1 patient severe subaortic left ventricular outflow tract obstruction developed after repair of an interrupted aortic arch. At reoperation 3 months after the initial repair the patient went into cardiac arrest at anesthesia induction and could not be saved. One patient in whom recent echocardiography had shown no residual defects or cardiac dysfunction died of sudden infant death syndrome 11 months after the operation. One patient died 6 months after the operation of intractable sepsis related to a bowel stricture. This patient had acquired necrotizing enterocolitis during the period of attempted medical management before referral for cardiac surgery. At the time of the operation the necrotizing enterocolitis had resolved; however, a late stricture developed. One patient died after reoperation for mitral valve replacement and subaortic obstruction. This patient, who initially was seen with coarctation and later proved to have the Shone complex, had intractable bleeding after the reoperation and could not be separated from bypass. One patient with familial distichiasis lymphedema syndrome acquired fungal sepsis and died 2 months after the operation. One patient with tetralogy of Fallot, major aorta-pulmonary collaterals, and DiGeorge syndrome was readmitted to the hospital several times with pulmonary infections and died of sepsis 6 months after the operation.

Actuarial survival was $82 \%$ at 1 year and beyond (Fig 2 ). Of the factors analyzed for association with poorer survival across time by univariate Cox regression, longer cardiopulmonary bypass time $(P=.002)$, complex anomalies $(P=.03)$, and a diagnosis of truncus arteriosus $(P=$ $.03)$ were found to correlate to a statistically significant degree. When these were entered into multivariate Cox regression analysis, only longer cardiopulmonary bypass time remained significant $(P=.001)$.

Late reinterventions. Eight patients underwent a total of 10 reinterventions, either surgical $(n=8)$ or by catheter $(n=2)$. In 1 patient the right pulmonary artery was successfully dilated 3 months after repair of aorta- pulmonary septal defect associated with interrupted aortic arch. Two patients acquired subvalvular $(n=2)$ or valvular $(\mathrm{n}=1)$ aortic stenosis after repair of interrupted aortic arch. One patient underwent a successful Ross procedure 4 months after the first operation. In the other case the aortic valve was dilated successfully at cardiac catheterization 8 months after the operation. One month later this patient underwent a surgical enlargement of the left ventricular outflow tract. Two patients with truncus arteriosus underwent replacement of the right ventricle-to-pulmonary artery conduit 13 and 24 months after the operation. Three patients who initially underwent coarctation repair required reoperation. One of these acquired bronchial compression 3 months after coarctation repair; this was corrected with aortopexy. Another required mitral valve replacement and then repair of subaortic stenosis 3 and 4 months after coarctation repair, respectively, after she turned out to have Shone complex. The third required repair of recurrent coarctation 2 months after the operation.

Actuarial freedom from reintervention was $91 \%$ at 1 year and beyond (Fig 2). None of the preoperative and operative factors analyzed correlated with shorter freedom from reintervention.

Residual or new cardiac lesions. Follow-up echocardiography performed at a median of 29 months (range 9-51 months) after initial repair revealed the following abnormalities. One patient had mild aortic regurgitation 48 months after an arterial switch operation. Two patients who had undergone repair of tetralogy of Fallot (1 with pulmonary atresia) 15 and 17 months earlier had mild pulmonary stenosis and moderate pulmonary regurgitation. One patient had mild residual coarctation with moderate hypoplasia of the distal arch 40 months after repair of aortic coarctation. A patient who had undergone repair of complete atrioventricular septal defect was found to have mild mitral regurgitation 46 months after the operation. A patient with truncus arteriosus had moderate to severe (gradient of 70 $\mathrm{mm} \mathrm{Hg}$ ) conduit stenosis develop 44 months after the operation. Two patients who underwent repair of interrupted aortic arch had subaortic stenosis with gradients of 40 and $50 \mathrm{~mm} \mathrm{Hg} 12$ and 15 months after the operation, respectively.

Follow-up cardiac medications. At the time of crosssectional follow-up 8 patients were taking cardiac medications. These included furosemide $(n=4)$, digoxin ( $n$ $=2)$, captopril $(\mathrm{n}=1)$, and nifedipine $(\mathrm{n}=1)$.

\section{Discussion}

Advances made during the past several decades have improved outcomes after neonatal cardiac surgery; 
however, low birth weight is still considered by many to be a contraindication to cardiopulmonary bypass and anatomic repair of even relatively simple cardiac defects. Some centers with experience report low birth weight as a risk factor for early mortality after corrective cardiac operations. ${ }^{6,7}$ In general, however, there has been little focus in the literature on surgical treatment of premature and low birth weight infants. Recently Pawade and associates ${ }^{6}$ reported on a series of 60 patients with low birth weight who underwent operations for various congenital heart defects, with a $16.5 \%$ early mortality rate and a $13.3 \%$ late mortality rate. Actuarial survival at 100 months was $67.5 \%$. In their experience the risk factors for early death after the operation in patients smaller than $2500 \mathrm{~g}$ were preoperative metabolic acidosis, univentricular palliation, duration of cardiopulmonary bypass, and postoperative low cardiac output. In that series the causes of death in patients undergoing univentricular and biventricular repairs were not clearly discussed. The authors suggest that it is intuitively obvious to assume that the mortality rate would be higher among the low birth weight babies because of complications of cardiopulmonary bypass.

Our experience suggests that complete repair not only of simple and moderately complex heart defects but even of highly complex heart defects can be achieved with good results in patients who weigh less than $2500 \mathrm{~g}$. There were 10 early deaths in our series. Although cardiopulmonary bypass and aortic crossclamp times were significantly longer for patients who died than for those who survived, it is likely that the mortality rate was not associated with bypass and cardioplegic arrest per se but was associated with the higher complexity of the lesions that required this prolonged circulatory support. Longer cardiopulmonary bypass time was also the only independent risk factor for poorer survival across time. Of the 8 late deaths, 4 were related to cardiac causes and 4 were of noncardiac causes. Two deaths were preventable and 1 was related to progression of uncorrectable disease.

Chang and colleagues ${ }^{10}$ reported on a series of 100 low birth weight and premature patients with congenital heart disease who were managed with different protocols. Among patients in whom intervention was performed early the mortality rates were $18 \%$ with corrective procedures and $22 \%$ with palliative procedures. In the group in which intervention was delayed, there was a $23 \%$ interim mortality rate. We agree with Chang and colleagues ${ }^{10}$ that delayed intervention does not confer any benefit and may in fact increase morbidity and mortality. In our experience delay in inter- vention was associated with increased complications, including ventilatory dependency, failure to thrive, absence of weight gain, sepsis, chronic pulmonary disease, necrotizing enterocolitis, and acute renal failure.

Previous reports have not addressed the issue of late complications and reinterventions after cardiac operations in premature and low birth weight infants. Our experience suggests that these occur at rates similar to those after operations on term neonates. It is necessary to closely follow up patients who have received conduits, because conduits implanted in these patients are generally small (in this series the allograft conduits were all $\leq 10 \mathrm{~mm}$ in diameter). Similarly, patients with interrupted aortic arch commonly have subaortic left ventricular outflow tract obstruction develop. Both of these situations led to a late death in our series, which illustrates the need for aggressive and objective cardiac evaluation in this group of patients to ensure that timely intervention can be performed.

It is logical to assume that correcting the cardiac defect will influence the cardiovascular physiology toward normal status and may be beneficial to pulmonary and other organ systems. There is evidence that growth is better after earlier repair of congenital heart lesions than after later repair. ${ }^{11}$ On the basis of weight gains observed in patients in this study, it appears that growth is also improved in premature and low birth weight infants who undergo early cardiac operative repair. Growth is similar to that seen among low birth weight and premature babies without cardiac disease, with babies with lower birth weights at lower percentiles of growth. ${ }^{12}$ There is an extensive body of literature dealing with the issue of neurologic development in low birth weight and premature babies, and it is clear that the incidence of developmental impairment rises with decreasing birth weight in this group of infants. ${ }^{12}$ It is reasonable to assume that development after surgical repair of congenital heart lesions, at least among those children without associated syndromes, will be brought to a level comparable to that observed among neonates of similar birth weight with no congenital cardiac anomalies. Although we did not specifically investigate every patient for perioperative intracerebral hemorrhage, no major neurologic complications were encountered that would suggest cerebral bleeding after bypass. Also, we currently make all efforts to avoid the use of circulatory arrest to prevent any possible attendant neurologic complications.

Delay in referral for intervention remains among the most persistent difficulties in the overall management of these infants. The reluctance to refer patients for surgical correction appears to be due to the widely preva- 
lent notion that surgery requiring cardiopulmonary bypass in these patients carries an inordinately high risk of death or morbidity. It seems, however, that this trend has started to change significantly in recent years. We cannot definitively resolve the question of whether risk of repair is equivalent or higher for premature infants than for term infants with the same lesions; however, this is not really the relevant issue. Even if one believes that prematurity or low birth weight does carry increased risk, the more relevant question is how the risk of repair compares to the risk of care involving medical management and delay in repair. Our results indicate that early repair carries lesser morbidity and that delay in repair carries extraordinary morbidity. We currently encourage referral for corrective surgery early after diagnosis if failure to thrive is present. Early intervention may also favorably affect the cost of care for these patients.

Complete repair of simple and moderately complex congenital heart defects can be performed safely and effectively in premature and low birth weight infants. In our experience even extremely complex lesions can be repaired effectively. An argument might be made that repair in the premature infant of some of these extremely complex lesions, such as double homograft repairs, may not be the most efficient use of resources. This becomes a philosophic or economic argument. Without taking a strong position on this issue, our success with these complex cases does underscore the point that the simpler lesions should be approached more aggressively with the anticipation of reliable outcome.

\section{REFERENCES}

1. Fyler D. Report of the New England Regional Infant Cardiac Program. Pediatrics 1980;65(suppl):377-461.

2. Kramer HH, Trampisch HJ, Rammos S, Giese A. Birth weight of children with congenital heart disease. Eur J Pediatr 1990;149: 752-7.

3. Rosenthal GL, Wilson PD, Permutt T, Boughman JA, Ferencz C. Birth weight and cardiovascular malformations: a populationbased study. Am J Epidemiol 1991;133:1273-81.

4. Kulkarni P, Hall RT, Rhodes PG, Sheehan MB. Postneonatal infant mortality in infants admitted to a neonatal intensive care unit. Pediatrics 978;62:178-83

5. Allen DM, Buehler JW, Samuels BN, Brann AW. Mortality in infants discharged from neonatal intensive care units in Georgia. JAMA 1989;261:1763-6.

6. Pawade A, Waterson K, Laussen P, Karl TR, Mee RBB. Cardiopulmonary bypass in neonates weighing less than $2.5 \mathrm{~kg}$ : analysis of the risk factors for early and late mortality. J Card Surg 1993;8:1-8.

7. Kirklin JK, Blackstone EH, Kirklin JW, McKay R, Pacifico AD, Bargeron LM. Intracardiac surgery in infants under age 3 months: incremental risk factors for hospital mortality. Am J Cardiol 1981;48:500-6.
8. Castaneda AR, Mayer JE, Jonas RA, Lock JE, Wessel DL, Hickey PR. The neonate with critical congenital heart disease: repair-a surgical challenge. J Thorac Cardiovasc Surg 1989; 98:869-75.

9. Castaneda AR, Jonas RA, Mayer JE, Hanley FL, editors. Cardiac surgery of the neonate and infant. Philadelphia: WB Saunders; 1994. p. 23-39.

10. Chang AC, Hanley FL, Lock JE, Castaneda AR, Wessel DL. Management and outcome of low birth weight neonates with congenital heart disease. J Pediatr 1994;124:461-6.

11. Weintraub RG, Menahem S. Growth and congenital heart disease. J Paediatr Child Health 1993;29:95-8.

12. Hack M, Klein NK, Taylor HG. Long-term developmental outcomes of low birth weight infants. Future Child 1995;5:176-96.

\section{Discussion}

Dr Roger B. B. Mee (Cleveland, Ohio). This is an important concept. I think that your intuitive logic set out in this report on early repair will be proved correct. I believe that your assumption that the risk of biventricular repair in these very small children is not different from that in older neonates is probably not quite true yet, however, and I would like to illustrate that from our own experience.

At the Royal Children's Hospital in Melbourne from 1979 to 1990 , we reported the cases of 60 patients smaller than 2.5 $\mathrm{kg}$, with a mean weight of $2.1 \mathrm{~kg}$ and a mean gestational age of 34 weeks. These were all patients who underwent cardiac operations, and they also included patients who underwent palliative heart operations. The early and late mortality rates for this group of 60 patients were $16 \%$ and $13 \%$, respectively. If we took out the univentricular repairs on cardiopulmonary bypass, the mortality rate fell to $12 \%$. In that univentricular group the mortality rate was $50 \%$, as in your own experience. During a similar period from 1984 to 1990, however, 296 neonates of all ages underwent biventricular repair on cardiopulmonary bypass with a mortality rate of $2 \%$. I can add that in my more recent experience at the Cleveland Clinic I think we have seen some further improvement. For heart repair of infants smaller than $2.5 \mathrm{~kg}$ from 1993 to 1998 , whether univentricular or biventricular repair, the mortality rate is now 5\%. For biventricular repair in older neonates, however, it remains $2 \%$ or less. I therefore think that age is still a risk factor.

In the last 15 to 20 years there have been important improvements in specialization in congenital heart disease and in surgery for these conditions. I think of most importance was the development of small-body technology, particularly the understanding of perfusion in small bodies. This leads me to some questions. The Melbourne method and the Cleveland Clinic method have also avoided circulatory arrest wherever possible and do these repairs on cardiopulmonary bypass. Our approach has been a little different, however. We have used aggressive $\alpha$-adrenergic blockade and high-flow, low-pressure cardiopulmonary bypass. If you are concerned about circulatory arrest, what is the logic of using low-flow cardiopulmonary bypass when you have already cannulated to do the operation under cardiopulmonary bypass? 
Also, can you derive from your experience the impact of tracheobronchomalacia or bronchopulmonary dysplasia in these small babies? In our experience this had a profound effect on the long-term results. I wonder whether in your outliers, in terms of time in intensive care and time in the hospital, this was an important point. If these children already have these problems, then the repair of their cardiac lesions may not make too much difference in the time that they have to spend on a ventilator and the time in intensive care.

I also wonder you why you included 14 closed procedures in this report, in which the focus is clearly on how to do cardiopulmonary bypass in very small babies. Can you separate out the mortality rate for those closed procedures from that for the open procedures?

Finally, we agree with you entirely about the apparently low risk, which is a surprise, for intracerebral hemorrhage associated with cardiopulmonary bypass in these children. How would you manage a small baby who has a high-flow lesion and is known to have an intraventricular hemorrhage? How long do you wait before performing cardiopulmonary bypass?

Dr Reddy. First, I do not contest the fact that age and weight still remain important risk factors in this group of patients. Our message was that waiting carries a higher morbidity and risk. The risk of surgery certainly is more than for a neonate with the normal birth weight. As your own data demonstrate, with experience your mortality rate dropped to $5 \%$. The mortality rate is going to decrease further, as we have seen with neonatal cardiac surgery.
To address your questions, we routinely use deep hypothermia with low-flow cardiopulmonary bypass. We also use $\alpha$ adrenergic blockers, namely phentolamine hydrochloride (INN: phentolamine), for cooling and rewarming. We prefer to use low-flow bypass rather than high flow because there is no evidence to suggest that higher flows are beneficial during deep hypothermia. Low-flow bypass is adequate for tissue oxygenation and keeps the surgical field relatively dry. Since the cannulas are in place, the amount of bypass flow is a matter of surgeon preference until there is evidence to suggest one technique is beneficial.

We included the nonpump cases to report our total experience. Even if you exclude the 14 nonpump cases in this report, 88 patients still have undergone complete repairs of complex lesions with an $11 \%$ mortality.

Tracheomalacia is an important cause of morbidity and did result in prolonged ventilatory support in some patients. Also, I think chronic lung disease can be minimized by early repair of complex heart defects in these small babies.

Intracranial bleeding often has been an important concern with the neonatologists. We certainly agree with your experience that intracranial bleeding has not been an issue with our group. With respect to the question of when should we operate if a patient has a hemorrhage, I think that there are no data on the group of patients who have had recent hemorrhage. I would say that waiting for a few days may be sufficient if the patient has symptoms. If the patient has no symptoms, however, I think one should wait at least 1 or 2 weeks before doing the open procedure with cardiopulmonary bypass. 